\title{
Effects of Abiotic Factors on the Geographic Distribution of Body Size Variation and Chromosomal Polymorphisms in Two Neotropical Grasshopper Species (Dichroplus: Melanoplinae: Acrididae)
}

\author{
Claudio J. Bidau, ${ }^{1}$ Carolina I. Miño, ${ }^{2}$ Elio R. Castillo, ${ }^{3,4}$ and Dardo A. Martín ${ }^{3,4}$ \\ ${ }^{1}$ Departamento de Ingeniería en Biotecnología, Universidad Nacional de Río Negro, Sede Alto Valle, Subsede Villa Regina, \\ Tacuarí 669, 8336 Villa Regina, Argentina \\ ${ }^{2}$ Departamento de Genética e Evolução, Universidade Federal de São Carlos, Rodovia Washington Luís SP-310 km 235, \\ 13565-905 São Carlos, SP, Brazil \\ ${ }^{3}$ Laboratorio de Genética Evolutiva, Universidad Nacional de Misiones, Félix de Azara 1552, 3300 Posadas, Argentina \\ ${ }^{4}$ CONICET, C 1033 AAJ Buenos Aires, Argentina
}

Correspondence should be addressed to Claudio J. Bidau, bidau47@yahoo.com

Received 19 August 2011; Revised 28 December 2011; Accepted 3 January 2012

Academic Editor: Matilda Savopoulou-Soultani

Copyright ( $(2012$ Claudio J. Bidau et al. This is an open access article distributed under the Creative Commons Attribution License, which permits unrestricted use, distribution, and reproduction in any medium, provided the original work is properly cited.

\begin{abstract}
We review the effects of abiotic factors on body size in two grasshopper species with large geographical distributions: Dichroplus pratensis and D. vittatus, inhabiting Argentina in diverse natural habitats. Geographical spans for both species provide an opportunity to study the effects of changes in abiotic factors on body size. The analyses of body size distribution in both species revealed a converse Bergmannian pattern: body size is positively correlated with latitude, altitude, and seasonality that influences time available for development and growth. Allen's rule is also inverted. Morphological variability increases towards the ends of the Bergmannian clines and, in D. pratensis, is related with a central-marginal distribution of chromosomal variants that influence recombination. The converse Bergmannian patterns influence sexual size dimorphism in both species but in different fashions. Body size variation at a microspatial scale in $D$. pratensis is extremely sensitive to microclimatic clines. We finally compare our results with those for other Orthopteran species.
\end{abstract}

\section{Introduction: Ecogeographic Rules, Body Size, and Abiotic Factors}

Body size, one of the most important characteristics of animals, is strongly influenced by abiotic factors $[1,2]$. One of the main causes of the importance of body size in determining many characteristics of the life history of organisms is that it scales with metabolic rate which, in turn, influences the rate at which an individual grows, acquires resources, and reproduces [3]. In Orthoptera, a interspecific analysis using 32 species of 7 families (both Ensifera and Caelifera) showed that the scaling exponent between metabolic rate and body size was 1.06 [3] supporting the model of Kozlowski et al. $[4,5]$ that cell size and number influence the metabolic scaling of organisms.
The influence of body size in a large number of life history characteristics of organisms including grasshoppers has been repeatedly stressed [2, 6-8]. Examples of this in grasshoppers are the relationship between body size and fecundity [7] or survival [9]. Thus, analyzing large-scale geographic variation of body size in different organisms is of importance in order to understand both the abiotic and biotic factors that may modify it through several mechanisms and the ecological and evolutionary consequences of this variation $[2,10-12]$.

The concept that abiotic factors are relevant to the evolution and adaptation of living beings has been present since the early days of modern biology [13-15]. Because abiotic factors vary geographically, their effects on organisms should change in consequence. A number of the so-called 
“ecogeographic rules” (Bergmann's rule, Allen's rule, and others) try to describe geographic patterns of body size observed across the geographic (essentially latitudinal and altitudinal) distributional range of species. Bergmann's rule [16] was originally formulated for endothermic animals (mammals and birds) at an interspecific scale. This rule states that body size tends to increase with latitude (or altitude) because of the ecological advantage of being larger, thus having lower surface/volume ratio, when temperature is lower. Heat loss is minimised (or heat conservation is increased) due to a larger body size. Allen's rule [17] is usually seen as a complement to Bergmann's rule because it describes geographic patterns of decreases in relative size of protruding parts of animals (ears, tails, wings, and limbs) as latitude increases (and mean temperature decreases), as a means for avoiding heat loss. Another important ecogeographic principle relating to adaptation to different environments both within and between species is Gloger's rule [18], which states that birds in climates with high relative humidity tend to be darker than conspecifics in climates with low relative humidity. However, this rule has not been thoroughly explored, especially in insects. A further ecogeographic rule, Jordan's rule or the Law of Vertebrae [19], states that the number of vertebrae in fish increases with latitude and thus decreases with temperature. In this sense it intersects with Bergmann's rule, but also with many other possible environmentally and genetically related mechanisms [20], and of course is not applicable to insects.

It is important to note that all these ecogeographic rules proposed, at their inception, a thermoregulatory explanation for the observed clinal trends (either latitudinal or altitudinal [21]). However, there has been growing concern that these patterns are probably the result of many factors (abiotic and biotic) acting jointly, which makes the situation far more complex than originally thought [20, 22-24], a suggestion that was already present in an early paper by Scholander [25].

With time, Bergmann's and Allen's rules became modified in their original sense. Both Mayr and Rensch [21, 2629] transformed the original concept of Bergmann's (and by extension, Allen's) rule to an intraspecific pattern: races or populations (not necessarily species) varied in size according to temperature gradients. Also, a number of studies were undertaken to try to apply these rules to ectotherms, that of Ray being one of the first [30]. However, his results [30] were inconclusive mainly because he freely compared different kinds of ectotherms (including insects and amphibians) and mechanisms underlying ecogeographic patterns in different organisms that probably obey different mechanisms. In fact, in the case of endotherms for which the ecogeographic rules were originally formulated, a number of discrepancies occur and it is not always possible to explain the geographic body size trends by simple thermoregulatory models. This situation becomes more complex when trying to verify the rules in ectotherms that, in most cases, regulate body temperature behaviourally, as is the case of most studied Orthoptera [31-35].

For endotherms, a number of non-Bergmannian physiological or ecological explanations have been developed to explain clinal patterns of body size variation, especially when this variation does not conform to Bergmann's rule [36-38]. This situation is complicated in ectotherms and particularly in insects, which tend to show geographic body size patterns that represent a continuum between fully empirical Bergmannian trends to its converse [39] and where classical thermoregulatory explanations are difficult to apply $[10,11]$.

We have studied two closely related species of Neotropical Melanopline grasshoppers, Dichroplus pratensis and D. vittatus, both of wide geographic distribution in Argentina in order to describe and understand their patterns of body size variation across climatic gradients.

\section{Study Species}

Dichroplus pratensis Bruner, 1900, and D. vittatus Brunner, 1900, belong to a large genus of Melanopline grasshoppers widely distributed in South America. Both species have the largest geographic distributions within the group, essentially in Argentina. Although Dichroplus has been recently the subject of revision and a number of species were placed in new genera, the maculipennis group, containing 9 species, seems to be well based and monophyletic on the grounds of structure of the phallic complex and external morphology [40].

Dichroplus pratensis distribution spans more than 23 degrees latitude, from the Puna highlands of Jujuy province to Santa Cruz province in Southern Patagonia. It is found from 0 to at least 2,500 masl, and longitudinally it is found from the Atlantic Ocean shore to the Andes [10, 12]. D. pratensis is more frequent in elevated, dry grasslands. It is found in an astonishing variety of habitats including the Patagonian steppe, the Puna highlands, and the humid Pampas. It is obviously a species of wide ecological tolerance, which is probably related to its nonselective polyphagous herbivorous habits. However, there is some evidence that it prefers forbs, which would explain its presence in nongrassland territory [41].

Dichroplus vittatus also has a wide distribution in Argentina partially overlapping that of $D$. pratensis although only seldom both species are found in strict sympatry, probably due to competitive exclusion. D. vittatus is more common in semiarid and arid habitats, and populations have been found at over 3,000 masl in Catamarca and La Rioja provinces [40]. Large populations are found in central Chubut on natural grasses and on "Jarilla" (Larrea divaricata) in the Monte phytogeographic region of Argentina [40]. Both species are univoltine, and the length of their adult reproductive periods depends largely on latitude and altitude $[10,11]$.

Twenty five population samples of adult D. pratensis Bruner (343 males, 352 females) were collected at localities from Argentina spanning $22^{\circ}$ of latitude and 0 to $2,474 \mathrm{~m}$ elevation during February and March, 2001. Population samples of adult $D$. vittatus Bruner were obtained at nineteen Argentine localities (190 males and 174 females) spanning almost $20^{\circ}$ of latitude and $36 \mathrm{~m}$ to $2,758 \mathrm{~m}$ above sea level during February and March, 2001. We used SPSS 
for Windows (Statistical Package for the Social Sciences) software to perform all statistical tests, mainly OLS regression and parametric and nonparametric correlation between body size estimators and geographic and climatic variables. Reduced major axis (RMA) regression was used in tests of allometry and sexual size dimorphism (SSD). Principal components analysis (PCA) was usually performed to reduce dimensionality of predictors because most environmental variables tend to show a high degree of colinearity. Prior to statistical analysis, all measurements were log-transformed and then tested for normality using the KolmogorovSmirnov test to determine the appropriateness of subsequent parametric or nonparametric analysis.

2.1. Clinal Variation of Body Size in Dichroplus pratensis and D. vittatus: The Converse to Bergmann's Rule. Bergmannian patterns in insects remain controversial. Some species or species groups tend to show clinal variation of increasing body size or body mass towards higher latitudes or altitudes and lower temperatures. However, in a large number of cases converse trends (or even the absence of a trend) have been observed at intra- and interspecific levels [39, 42-45].

We studied geographic body-size variation in 25 populations of Dichroplus pratensis (along more than 22 degrees of latitude $(S)$ and between 0 and almost $2,500 \mathrm{~m}$ altitude) and 19 populations of Dichroplus vittatus spanning 20 degrees of latitude and 2,700 $\mathrm{m}$ altitude. Geographic size variation is wide in both species. Mean male body size (populational means) varied between 18.9 and $26.4 \mathrm{~mm}$ in D. pratensis and 16.43 and $21.62 \mathrm{~mm}$ in D. vittatus. For females, size ranges were $22.2-28.2$ and $20.26-28.13 \mathrm{~mm}$, respectively.

Using mean body length of each sex and factors obtained from PCA analyses of six morphometric linear characters (body length, length of left hind femur, length of left hind tibia, length of tegmina, middorsal length of pronotum and height of pronotum), it was shown that $D$. pratensis and $D$. vittatus follow the converse to Bergmann's rule, becoming smaller at higher latitudes and altitudes (Table 1). In D. pratensis variability of body size increased with latitude and altitude in both sexes (Table 3). Body size trends were significantly correlated with mean ambient temperatures (annual mean, minimum, and maximum), precipitation (annual mean, minimum, and maximum), and two estimators of seasonality, the difference between the maximum and minimum temperatures and the difference between maximum and minimum precipitation; all nonparametric correlations were positive (Table 2). Body size was also positively and significantly correlated with actual evapotranspiration (AET), a measure of primary productivity, and with potential evapotranspiration (PET), a measure of ambient energy (Table 2). Some allometric relationships also showed geographic variation (see the section on Allen's rule) $[10,46]$. We proposed that the observed decrease in size with latitude and the increase in morphological variability are joint consequences of the shortening of the growing season, the increasing seasonality and climatic unpredictability and lower primary productivity towards the south (as represented by AET) and that the species exhibits protandry, which contributes, in the south, to smaller and more variably sized males and smaller but more constant body sizes in females. A further factor increasing variability at marginal localities has a genetic component (see below).

A parallel study was performed in the closely allied $D$. vittatus. This species also follows the converse to Bergmann's rule latitudinally but not altitudinally where no significant trends were observed (Table 1). For males, variability of body size increased with latitude but not altitudinally (Table 3 ). Both trends (size and variability) were significantly and positively correlated with mean annual temperature and minimum annual temperature and two estimators of seasonality: the coefficients of variation of mean annual temperature (negative correlation) and mean annual precipitation (positive correlation) (Table 1). As in D. pratensis, some allometric relationships also showed geographic variation. It was suggested that the observed decrease in size with latitude together with the increase in morphological variability is a consequence of a number of factors, which parallel those that predict body size in the sister species: the shortening of the growing season southwards, the increasing seasonality and climatic unpredictability, and the fact that the species exhibits protandry which contributes to smaller and more variable size in males and smaller but more constant body sizes in females [10].

Thus, both species seem to obey the same environmental pressures (either because of phenotypic plasticity or natural selection in different habitats), and the correlations with abiotic factors result from the large geographic distribution of both species which extend progressively into areas of increasing seasonality, lower resource availability, and shorter time for growth, development, and reproduction. These results are in close agreement with those obtained for crickets [43-45] but were reported by us for the first time in species of Acrididae.

2.2. Allen's Rule in D. pratensis and D. vittatus. The relative length of protruding parts of endothermic animals tends to decrease with increasing latitude and altitude as Allen proposed almost a century and a half ago [17, 47]. This pattern, as Bergmann's rule, has been usually regarded as a means of decreasing area/volume ratios in order to minimize heat loss and as a thermoregulatory evolutionary adaptation [48]. It has recently been suggested that a further physiological explanation could explain the effect of temperature on limb length in endotherms. In an experiment using mice it was shown that peripheral tissue temperature closely reflects housing temperature in vivo. Also, tissue temperature was significantly correlated with the proliferation of chondrocytes in in vitro cultures of metatarsals without vasculature [49]. This provides a novel, nonthermoregulatory explanation to limb length variation by a direct effect of ambient temperature.

However, with very few exceptions, application of Allen's rule to insects has not been explored [30, 48]. We studied the geographic variation of three morphometric characters in relation to body size in Dichroplus vittatus and D. pratensis to test Allen's rule in these ectotherms. Since both 
TABLE 1: Correlation coefficients and their statistical significance between an estimator of body size (BL: body length) and several geographic and environmental predictors for males $(\mathrm{M})$ and females $(\mathrm{F})$ of two grasshopper species.

\begin{tabular}{|c|c|c|c|c|}
\hline \multirow{3}{*}{ Variable* } & \multicolumn{4}{|c|}{ Correlation coefficient $(P)$} \\
\hline & \multicolumn{2}{|c|}{ Dichroplus pratensis } & \multicolumn{2}{|c|}{ Dichroplus vittatus } \\
\hline & $\log _{10} \mathrm{MBL}$ & $\log _{10} \mathrm{FBL}$ & $\log _{10} \mathrm{MBL}$ & $\log _{10} \mathrm{FBL}$ \\
\hline LAT & $-0.70(<0.001)$ & $-0.76(<0.001)$ & $-0.64(0.003)$ & $-0.65(0.003)$ \\
\hline ALT & $-0.39 \mathrm{~ns}$ & $-0.51(<0.001)$ & ns & ns \\
\hline TMEAN & $0.71(<0.001)$ & $0.65(<0.001)$ & $0.52(0.021)$ & $0.60(0.006)$ \\
\hline TMAX & $0.70(<0.001)$ & $0.63(<0.001)$ & ns & ns \\
\hline TMIN & $0.59(0.002)$ & $0.53(0.007)$ & $0.58(0.010)$ & $0.70(0.001)$ \\
\hline CVT & ns & ns & $-0.67(0.002)$ & $-0.75(<0.001)$ \\
\hline TMm & $0.73(<0.001)$ & $0.44(0.029)$ & ns & ns \\
\hline PANNU & $0.56(0.004)$ & $0.40(0.044)$ & ns & ns \\
\hline PMAX & $0.43(0.031)$ & $0.42(0.039)$ & ns & ns \\
\hline PMIN & $0.48(0.014)$ & ns & $-0.53(0.020)$ & $-0.50(0.028)$ \\
\hline CVP & ns & ns & $0.56(0.012)$ & $0.52(0.024)$ \\
\hline PMm & $0.49(0.013)$ & $0.42(0.039)$ & $0.47(0.043)$ & ns \\
\hline PET & $0.59(0.002)$ & $0.48(0.016)$ & ns & $0.46(0.047)$ \\
\hline AET & $0.48(0.014)$ & $0.50(0.011)$ & ns & ns \\
\hline WB & ns & ns & ns & ns \\
\hline
\end{tabular}

*LAT: latitude in decimal degrees; ALT: altitude in metres above sea level; TMEAN: mean annual temperature (in Celcius degrees); TMAX: mean annual maximum temperature; TMIN: mean annual minimum temperature; CVT: coefficient of variation of TMEAN; TMm: mean difference between maximum and minimum monthly temperatures; PANNU: total annual precipitation (in mm/year); PMAX: mean maximum monthly precipitation; PMIN: mean minimum monthly precipitation; CVP: coefficient of variation of PANNU; PMm: mean difference between maximum and minimum monthly precipitation; PET: potential evapotranspiration (the Priestley-Taylor equation); AET: actual evapotranspiration (the Thornthwaite formula); WB: water balance; ns = nonsignificant.

TABLE 2: Spearman correlation coefficients and their statistical significance (in parentheses) between the arsin-transformed proportions of three morphometric traits (F3L: femur 3 length; T3L: tibia 3 length; TeL: tegmina length) and body length (BL) with respect to latitude (LAT), altitude (ALT), and three selected abiotic factors (TMEAN: mean annual temperature; PMm: mean difference between maximum and minimum mean monthly precipitation; WB: water balance) in males and females of 25 and 19 populations of $D$. pratensis and $D$ vittatus, respectively.

\begin{tabular}{lcccccc}
\hline Species (sex) & arsin Proportion & LAT & ALT & TMEAN & PMm & WB \\
\hline \multirow{3}{*}{ D. pratensis $\mathrm{M}$} & F3L/BL & $0.55(0.004)$ & $-0.47(0.018)$ & $-0.03(\mathrm{~ns})$ & $0.19(\mathrm{~ns})$ & $0.73(<0.001)$ \\
& T3L/BL & $0.55(0.004)$ & $-0.68(<0.001)$ & $-0.10(\mathrm{~ns})$ & $0.04(\mathrm{~ns})$ & $0.57(0.003)$ \\
& TeL/BL & $0.53(0.006)$ & $-0.56(0.004)$ & $0.07(\mathrm{~ns})$ & $0.18(\mathrm{~ns})$ & $0.77(<0.001)$ \\
\hline \multirow{3}{*}{ D. pratensis $\mathrm{F}$} & F3L/BL & $0.63(0.001)$ & $-0.46(0.022)$ & $-0.61(0.001)$ & $-0.005(\mathrm{~ns})$ & $0.39(0.005)$ \\
& T3l/BL & $0.66(<0.001)$ & $-0.58(0.002)$ & $-0.61(0.001)$ & $-0.22(\mathrm{~ns})$ & $0.31(\mathrm{~ns})$ \\
& TeL/BL & $0.71(<0.001)$ & $-0.73(<0.001)$ & $-0.14(\mathrm{~ns})$ & $-0.13(\mathrm{~ns})$ & $0.64(0.001)$ \\
\hline \multirow{3}{*}{ D. vittatus $\mathrm{M}$} & F3/BL & $0.32(\mathrm{~ns})$ & $-0.10(\mathrm{~ns})$ & $0.10(\mathrm{~ns})$ & $-0.63(0.004)$ & $0.07(\mathrm{~ns})$ \\
& T3/BL & $-0.50(\mathrm{~ns})$ & $-0.05(\mathrm{~ns})$ & $0.32(\mathrm{~ns})$ & $0.70(0.001)$ & $-0.32(\mathrm{~ns})$ \\
& Te/BL & $-0.34(\mathrm{~ns})$ & $0.10(\mathrm{~ns})$ & $0.43(\mathrm{~ns})$ & $0.66(0.002)$ & $-0.11(\mathrm{~ns})$ \\
\hline \multirow{3}{*}{ D. vittatus $\mathrm{F}$} & F3/BL & $-0.32(\mathrm{~ns})$ & $0.06(\mathrm{~ns})$ & $0.07(\mathrm{~ns})$ & $0.51(0.026)$ & $-0.16(\mathrm{~ns})$ \\
& T3/BL & $-0.49(\mathrm{~ns})$ & $0.08(\mathrm{~ns})$ & $0.26(\mathrm{~ns})$ & $0.34(\mathrm{~ns})$ & $-0.33(\mathrm{~ns})$ \\
& Te/BL & $-0.60(0.007)$ & $0.002(\mathrm{~ns})$ & $0.54(0.016)$ & $0.61(0.006)$ & $-0.37(\mathrm{~ns})$ \\
\hline
\end{tabular}

ns = non-significant.

species follow the converse to Bergmann's rule owing to latitudinal and/or altitudinal variation in time available for growth and reproduction, geographic variation in body size proportions of protruding parts may obey differential allometric growth in different geographic areas owing to time constraints on development and growth imposed by abiotic factors that in turn regulate adult season and time available for reproduction (see above). Alternatively, it could reflect true Allenian variation related to thermoregulation. Body proportions (hind femur, hind tibia, and tegmina with respect to total body length measured from the tip of the head up to the distal portion of the hind femur length 
TABLE 3: Mean body length in mm (BL) and coefficients of variation (CV) in selected marginal and central populations of two species of grasshoppers. LAT: latitude in decimal degrees; ALT: altitude in metres above sea level.

\begin{tabular}{|c|c|c|c|c|c|}
\hline Species & Population & LAT & ALT & Male BL/CV & Female BL/CV \\
\hline \multirow{6}{*}{ D. pratensis } & Volcán & 23.92 & 2574 & $22.36 / 5.56$ & $24.34 / 4.69$ \\
\hline & Estación Mazán & 28.73 & 646 & $23.83 / 4.56$ & $26.48 / 5.71$ \\
\hline & Don Tomás & 36.68 & 175 & $24.24 / 4.00$ & $25.41 / 3.51$ \\
\hline & Olavarría & 36.92 & 162 & $22.57 / 3.95$ & $24.34 / 4.30$ \\
\hline & Diadema Argentina & 45.78 & 326 & $19.29 / 5.86$ & $22.18 / 6.21$ \\
\hline & Villa Rada Tilly & 45.95 & 0 & $18.21 / 6.33$ & $23.17 / 6.37$ \\
\hline \multirow{6}{*}{ D. vittatus } & Huacalera & 23.43 & 2758 & $17.30 / 4.05$ & $21.66 / 6.09$ \\
\hline & Santiago del Estero & 26.02 & 174 & $21.62 / 4.38$ & $24.83 / 3.71$ \\
\hline & Valle Fértil & 30.63 & 828 & $18.55 / 4.64$ & $24.68 / 2.35$ \\
\hline & Villa del Rosario & 31.57 & 248 & $19.19 / 3.65$ & $26.08 / 3.26$ \\
\hline & Toay & 36.57 & 174 & $16.77 / 7.69$ & $20.76 / 2.89$ \\
\hline & Playa Unión & 43.07 & 36 & $16.43 / 5.78$ & $20.26 / 8.29$ \\
\hline
\end{tabular}

when parallel to the longitudinal axis of the body) were studied by correlation/regression analyses with geographic and climatic variables (temperature, precipitation, evapotranspiration, and water balance) (Table 2). In D. pratensis, body proportions increased with latitude and decreased with altitude (Table 2). These results probably obey the effects of water balance and seasonality on final body size, and on the allometric growth of the three studied characters not being related to thermoregulation. In D. vittatus, a generally nonsignificant trend towards the decrease of the mean proportions of all three characters with increasing latitude was observed (Table 2). Nevertheless, also in this species, it is probable that the environmental gradient responds to seasonality factors (although not to water balance) that affect the length of growing season and, in consequence, body size and its allometric relationships. We conclude that the regularities in the geographic distribution of body proportions of $D$. pratensis and D. vittatus do not follow Allen's rule in the sense of thermoregulation and result from variables that determine growing season length and the allometric growth of different body parts, closely correlated with the converse Bergmannian body size trends [46].

\subsection{The Central Marginal Distribution of Chromosomal} Polymorphisms of D. pratensis and Its Relationship with Body Size and Abiotic Factors. Dichroplus pratensis has a standard all-telocentric chromosome complement of $2 n=$ $18+\mathrm{X} 0 \circ^{\top} / 18+\mathrm{XX}+$ but is polymorphic and polytypic for Robertsonian (Rb) fusions that involve the six larger autosomes (L1-L6). Each population may be polymorphic (or eventually may have become fixed) for one to three $\mathrm{Rb}$ fusions (except in monobrachial chromosomal hybrid zones in which four fusions may coexist), which vary in quality and frequency in different populations. Fusions in this species produce profound changes in inter- and intrachromosomal genetic recombination by reducing the number of linkage groups that assort independently and by creating, through a reduction of chiasma frequency, large pericentromeric recombination-free chromosomal regions that may house adaptive supergenes [50].

Distribution of $\mathrm{Rb}$ polymorphisms is not random in D. pratensis: different fusion systems characterize different chromosomal races that inhabit radically different environments. Moreover, the highest number of fusions and their highest frequencies are associated with ecologically optimal (central) environments. In these not highly seasonal habitats, primary productivity is high and resources are abundant in quantity and variety. Populations tend to be very large and extremely dense in some years. Rb frequencies decrease clinally and steeply towards the margins of the geographic distribution until in the most extreme environments (i.e., the Patagonian steppe towards south and the Puna highlands towards north) fusions completely disappear, populations being strictly monomorphic for the standard karyotype. Those extreme habitats are harsh, unpredictable, and highly seasonal. Populations are rare, very small, and of very low density, and the distribution of the species is extremely patchy and not continuous as in central habitats [50,51].

The central-marginal model relates the complex Rb polymorphisms with the distribution of abiotic and biotic factors along latitudinal and altitudinal gradients and variation in body size which, as stated before, follows the converse to Bergmann's rule. We have proposed that, in central regions, high frequencies of $\mathrm{Rb}$ polymorphism would maintain coadapted supergenes adaptive to these stable and favorable environments; thus, restriction of genetic recombination would be essential to impede supergenes breakdown through crossing-over. In marginal habitats, however, which are changing and unpredictable, where resources are low and populations probably endure continuous cycles of extinction and recolonisation, high recombination is essential for the liberation of genetic variability that would be the substrate of natural selection for allowing adaptation to these harsh environments.

The former was in part corroborated by studies of morphological diversity along the range of the species. It has been shown that, although body size decreases clinally 
TABLE 4: Reduced major axis (RMA) regressions of male body length on female body length under the null hypothesis of $\beta=1.0$ in Dichroplus pratensis and D. vittatus. $r$ : pearson's correlation coefficient; T: student's $t$-statistic; df: degrees of freedom; $P$ : probability; $\beta$ : slope of RMA regression; $S_{\xi}$ : standard deviation; $T$ : Clarke's T-statistic; CI: confidence interval; $a$ : RMA regression intercept.

\begin{tabular}{lccccccccccccc}
\hline \multicolumn{1}{c}{ Correlation coefficient } & \multicolumn{4}{c}{ RMA slope } \\
\hline SPECIES & TRAIT & $r$ & $t$ & df & $P$ & $\beta\left(S_{\xi}\right)$ & $T$ & df & $P$ & $95 \%$ CI & $a\left(S_{\xi}\right)$ & $95 \%$ CI \\
\hline D. pratensis & BL & 0.79 & 5.12 & 23 & $<0.001$ & $1.328(0.171)$ & 2.60 & 20.33 & 0.009 & $0.975,1.681$ & $-0.493(0.239)$ & $-0.988,0.002$ \\
D. vittatus & BL & 0.83 & 6.15 & 17 & $<0.001$ & $0.767(0.104)$ & 2.40 & 15.38 & 0.015 & $0.549,0.986$ & $0.221(0.143)$ & $-0.080,0.522$ \\
\hline
\end{tabular}

towards the margins, morphological variability increases significantly (especially in adult males) despite the fact that, in marginal populations, the time available for development and growth is much lower than in optimal central environments (Figure 1). This fact has been interpreted as a result of increased recombination and release of genetic variability (Figures $1(\mathrm{c})-1(\mathrm{f})$ ). The same phenomenon has been observed in the sister species, D. vittatus whose geographic distribution mostly overlaps that of $D$. pratensis (see below).

2.4. Rensch's Rule Is Affected by Bergmann's Rule or Its Converse. In 1950, Berhard Rensch [52] described, in phylogenetically related species (including mammals, birds, and carabid beetles), an interspecific pattern, now called Rensch's rule, by which sexual size dimorphism (SSD) tends to increase as general body size increases. Later, Rensch expanded his definition as follows: "In species of birds in which the male is larger than the female, the relative sexual difference (in size) increases with body size. If by way of exception, the females are larger than the males, as among many species of birds of prey, the opposite correlation applies, that is, the greater sexual difference is found in the smaller species". The latter has become to be considered the standard definition of Rensch's rule $[53,54]$ but its interpretation is ambiguous. Although in male-biased SSD the rule is usually clearly demonstrated, in the opposite situation (female-biased SSD) the situation is far from clear [55]. This is most relevant because in a vast majority of insects and particularly in grasshoppers females are usually larger than males. In grasshoppers, there are many cases of extreme female-biased SSD in families such as Proscopiidae, Ommexechidae, and Romaleidae but information regarding Rensch's rule is extremely scarce [56]. Furthermore, since patterns of SSD are probably heavily influenced by Bergmannian or converse-Bergmannian body size patterns, which in turn depend on clinal variation of abiotic factors [57], a clarification of Rensch's rule in grasshoppers is needed.

The case of both Dichroplus species here reviewed is clear in this respect: both species have overlapping geographic distributions in Argentina, and both are sister species belonging to the same Dichroplus species group (the " $m a c$ ulipennis" group) and follow the converse to Bergmann's rule. Although Melanoplinae Acrididae do not show extreme SSD, males and females are readily distinguished by size in the field and all species show female-biased SSD. However, both species exhibit completely opposite patterns of SSD regarding Rensch's rule.
SSD can be the result of sexual or natural selection. Due to male-male competition for access to females, SSD could favor an increase in male body size. On the other hand, larger size in females could be favored by natural selection since fecundity is directly correlated with body size $[56,58]$.

SSD occurs in both species across their geographical distribution ranges, also involving differences in allometry and shorter developmental times in males. In $D$. vittatus the degree of SSD increased significantly with general body size (classical definition of Rensch's rule), whereas in D. pratensis SSD decreased as body size increased (as predicted by the extended definition of Rensch's rule) (Table 4). A plausible explanation of SSD is that sexual selection favors a differential increase in female body size related to a preference by males for more fecund females. Given the close phylogenetic relationship between both species, the differences in SSD between them may be the result of differential natural and sexual selective pressures. In $D$. vittatus both sexes may be reacting differently to environmental conditions regarding body size, while in $D$. pratensis protandry could be the main factor behind SSD, although both react to ambient conditions following the converse to Bergmann's rule [58].

Considering that both species exhibit converse latitudinal Bergmannian patterns related to environmental conditions and that SSD depends on general body size according to Rensch's rule (independently of definition), the steeper latitudinal body size cline shown by males of $D$. vittatus with respect to females would be a consequence of male differential responsiveness to seasonality and season length, determining the decrease of SSD towards South.

2.5. Microspatial Body Size Variation in D. pratensis. In a recent study [59], variation in six morphological measurements in $D$. pratensis sampled at a microspatial scale within the Sierra de la Ventana chromosomal hybrid zone was analyzed. The Sierra de la Ventana region (Buenos Aires province, Argentina) is a heterogeneous environment spread over the southern portion of the transitional zone between wet and dry pampas of Argentina. As a consequence of the interaction among climatic and geological factors (i.e., 16 different vegetation units, transitional annual rainfall regime, and diversity of soils, environments, and topographical design) this region displays diverse microclimates (see references in [59]). Despite its habitat heterogeneity, the Sierra de la Ventana area belongs to the central, ecologically favorable, range for $D$. pratensis characterized by higher food availability and less strenuous environmental conditions [58]. In this hybrid zone, two chromosomal races, polymorphic for different $\mathrm{Rb}$ fusions, encounter and hybridize $[60,61]$. 


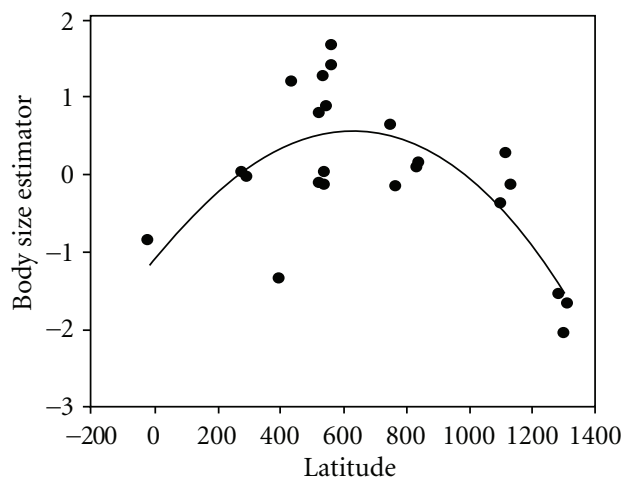

(a)

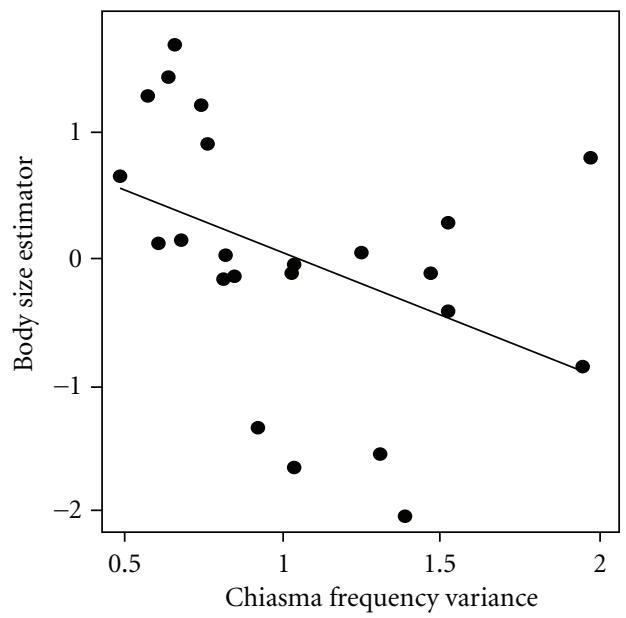

(c)

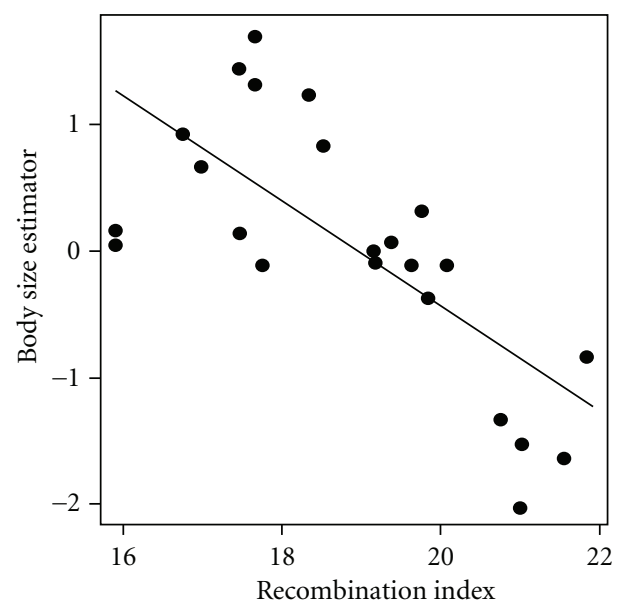

(e)

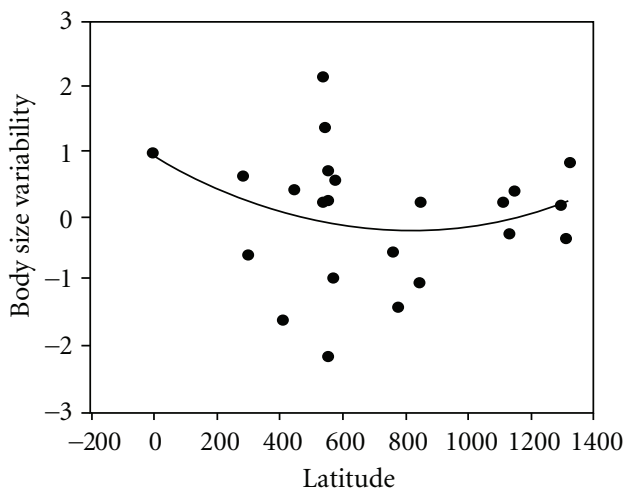

(b)

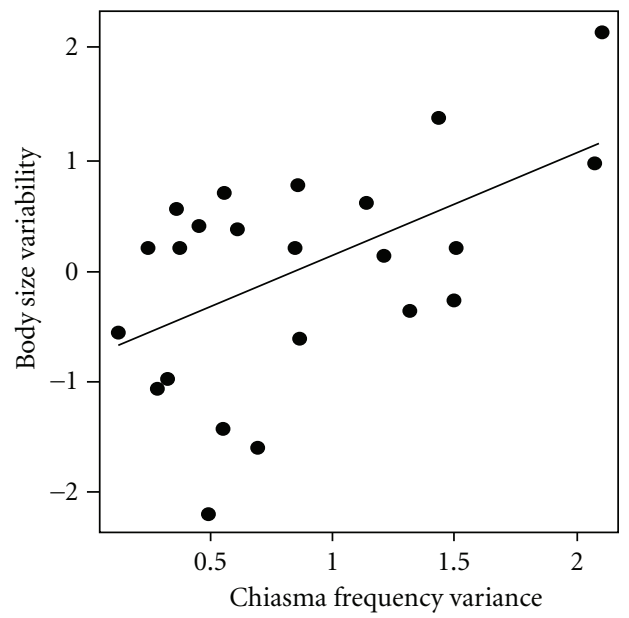

(d)

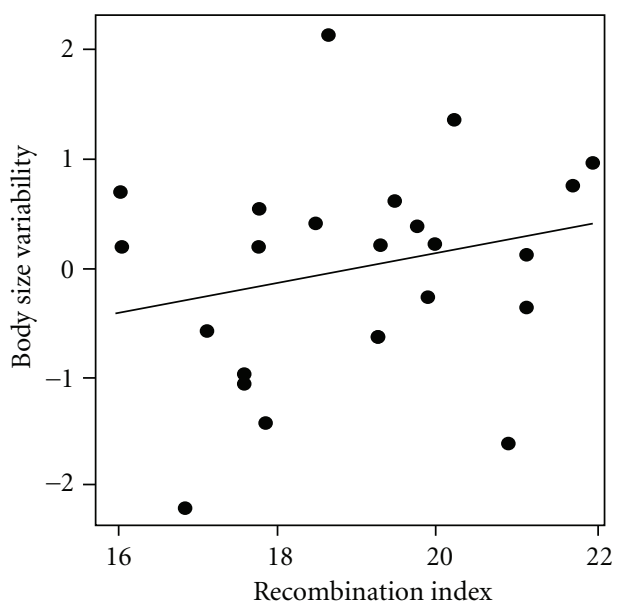

(f)

FIGURE 1: Regressions of body size and body size variability of $D$. pratensis on latitude and two estimators of genetic recombination. Body size and its variability are represented by the first and second principal components of a PCA analysis of six linear morphometric measurements and their coefficients of variation. PC1 showed high loadings for the six measurements and PC2 for the six CVs. (a) Distribution of body size along the studied gradient. Marginal populations show smaller body sizes than central ones. (b) Distribution of body size coefficients of variation along the studied gradient. Marginal populations show higher variability than central ones. (c) and (d) Regression of body size and body size variability on between-cell variance of mean chiasma frequency. Body size decreases but its variability increases with higher chiasma variance. (e) and (f) Regression of body size and body size variability on an ad hoc recombination index. Body size decreases but its variability increases with higher recombination frequency. 
The "Northern" race, widely distributed in central Argentina, polymorphic for fusions L1 and L6 (L1/L6) and L3 and L4 (L3/L4), contacts a geographically restricted "southern" race, polymorphic for fusions L1 and L2 (L1/L2), L3/L4, and L5 and L6 (L5/L6). Complex Rb heterozygotes with reduced fertility occur at this mosaic hybrid zone [51] and chromosome frequencies change abruptly over rather short distances and altitudes (ca. $<1,000 \mathrm{~m}$ and $<500 \mathrm{~m}$, resp.) with fusions L1/L2 and L5/L6 occurring more frequently at higher altitudes [51, 59].

Miño et al. [59] investigated morphometric (total body length, pronotum height and length, left third femur length, left third tibia length, and tegmina length), chromosomal, and molecular (genetic) variation in males and females of Dichroplus pratensis, at a microspatial scale. A microspatial altitudinal gradient was studied: samples were taken from the base to the top of Cerro Ceferino Hill, a hill of about $\sim 456$ masl. Both male and female grasshoppers showed extensive morphometric variation at a microspatial scale. Highly significant differences were observed between samples and sexes, as indicated by GLM (General Linear Model), with all six morphometric characters separately measured in both sexes from each sample as dependent variables [59]. Specifically for body length, significant differences were observed among grasshoppers from the hill base ( $\sim 40 \mathrm{masl})$ and the hill top ( $\sim 650$ masl). Insects from the hill base were smaller (mean/CV body length in males $=21.73 \mathrm{~mm} / 1.2 ;$ mean $/ \mathrm{CV}$ body length in females $=23.86 \mathrm{~mm} / 1.04$ ) than those from the hill top (mean/CV body length in males $=23.12 \mathrm{~mm} / 1.08$; mean/CV body length in females $=24 \mathrm{~mm} / 1.19$ ). In Miño et al. [59], body length was significantly positively correlated with altitude in males. Furthermore, a PCA performed to investigate the relationship between body size and altitude, revealed that the first PC, a size estimator, showed the highest loadings for the majority of traits. Also within the Cerro Ceferino hill the trend for male body size was significant and positive. However, no significant correlations between altitude and body size were apparent for females despite a slightly increasing trend.

An additional dimension of intraspecific morphometric variation was analyzed in Miño et al. [59], and sexual size dimorphism was also present in $D$. pratensis samples from a microspatial altitudinal gradient. Sexual size dimorphism was female-biased for all traits in most samples. However, there was no significant relationship between SSD and altitude (ALT) although third tibia length was significantly correlated with ALT in an inverse function. Also, in male grasshoppers from Cerro Ceferino, body length increased significantly and linearly with mean fusion frequency, with frequency of fusions L5/L6 and L3/L4. No trend was statistically significant in females. The body size pattern observed at a microspatial scale in $D$. pratensis [59] differentiates from that observed at a large geographic scale where size shows an inverse correlation with altitude and latitude $[10,12]$. It was proposed that in Sierra de la Ventana the body size trend is a likely consequence of habitat segregation of two forms well adapted to contrasting microhabitats within the hybrid zone; this zone, although environmentally heterogeneous, only represents a very small fraction of the species total geographic range and environmental variability.

In this study [59] it was also shown that chromosomal variation of insects was also correlated to microgeographic location: in the Cerro Ceferino Hill, the four fusions characteristic of the hybrid zone varied widely in the sampled grasshoppers, with mean frequency values $(F)$ ranging from 2.5 to 3.0. Fusion L1/L6 was only recorded at the hill base. The frequencies of L1/L2 and L5/L6 increased towards the top of the hill reaching fixation in most samples; fusion L3/L4, showed high frequencies in all samples. Mean fusion frequency and frequencies of fusions L1/L2, L3/L4, and L5/L6 were positively correlated with altitude.

Molecular variation in $D$. pratensis from the Cerro Ceferino, a microspatial altitudinal gradient within the Sierra de la Ventana hybrid zone, was also assessed by Miño et al. [59] using RAPD primers. Significant differences were found in mean heterozygosity values among samples from the hill base to the top, samples from the slope being the more genetically variable. Moreover, samples from the hill base and top were significantly differentiated genetically (as revealed by Wright's $1951 F_{S T}$; see Table 5 in [59]).

In conclusion, data of this study [59] revealed a pattern of morphological variation and genetic differentiation within very short distances in $D$. pratensis populations from Sierra de la Ventana hybrid zone. It was proposed that the observed pattern reflects local adaptation at a very small geographical altitudinal gradient, favored by differential adaptation of chromosomal hybrids (genotype combinations) that vary in fitness to heterogeneous abiotic and biotic conditions.

\section{Discussion and Conclusions}

The results reviewed in this paper have shown that two neotropical melanopline species, Dichroplus pratensis and $D$. vittatus, with largely overlapping but usually not locally sympatric geographic distributions, follow the converse to Bergmann's rule. These inverted patterns cannot be attributed to thermoregulatory responses but to interaction with abiotic environmental factors such as seasonality that shorten the time available for development, growth, and reproduction and others that control primary productivity and access to resources. Allen's rule was also not verified but a converse pattern or absence of pattern indicating that, again, thermoregulation is not involved in the proportion of protruding body parts. The observed trends are probably a byproduct of the converse Bergmannian pattern and allometric growth. The countergradient body size variation also indirectly affects Rensch's rule but in opposite ways in both species so that $D$. vittatus follows the rule while $D$. pratensis inverts it. It is important to note that the relationship between body size and abiotic factors produces in both cases a central-marginal size pattern, which in both species involves also an increase of size variability towards the margins. Furthermore, in D. pratensis the pattern is closely followed by a complex polymorphic chromosomal system that regulates genetic recombination probably as a selective response to increasing unpredictability of the environment 
towards the margins of the distribution. Most of these patterns are repeated at a microspatial scale in $D$. pratensis.

However, it is possible that the effect of abiotic factors on body size and life history characteristics follows different paths in different species. A brief survey of the orthopteran literature in this respect suggests the former but also highlights some common points. In the bushcricket Poecilimon thessalicus (Phaneropterinae), collected at three mountain ranges in eastern Greece, it has recently been demonstrated that individuals of populations from the eastern slopes were consistently larger than those from the western slopes. Since these size differences cannot be attributed to a large geographic distribution (less than 1 degree latitude and longitude although altitude varied between 400 and 1,800 masl), no large temperature differences are expected to exert profound effects on body size. Thus, the most probable explanation of this size variation is that, in the dryer western slopes, growing season is shorter thus producing smaller individuals [62].

Another study involving the flightless bushcricket Pholidoptera frivaldskyi analysed three extremely isolated populations of this species. This bushcricket is endangered and inhabits fragments of mountainous areas (550-1800 masl in elevation) at the Carpathian Mountains and montane areas in Bulgaria, Serbia, Bosnia, and Macedonia. However, it has not been recorded out of Slovakia for more than $40 \mathrm{y}$. Despite their isolation, all three populations did not show consistent differences in body size apart from the intrapopulational ones. This may indicate a similar environmental effect of ambient conditions on the phenotypic plasticity of the populations and a genetic uniformity aided by the small size of the populations and a relatively recent origin before fragmentation [63].

In a study of species composition and body size of Tettigoniid species in Atlantic coast salt marshes on Spartina alterniflora (Poaceae) communities (latitudinal range, $13.19^{\circ}$ ), Fabriciusová et al. [63] showed converse Bergmannian patterns for two species, Orchelimum fidicinium and Conocephalus spartinae. O. fidicinium, the largest species, dominated the tettigoniid community at low latitudes and C. spartinae, the smallest species, at high latitudes. Furthermore, both species showed a converse Bergmannian pattern at the intraspecific level, individuals being progressively smaller towards higher latitudes. According to the authors several factors might explain this shift in dominance and size trends, including changes in climate, plant phenology, and plant zonation patterns.

Altitudinal body size clines have been less explored in Orthoptera. However, recently, Ciplak et al. [64] have shown converse Bergmannian clines for a grasshopper (Oedipoda miniata) and a katydid (Poecilimon birandi) along a 2,000 m altitudinal gradient in Anatolia (Turkey). Although the authors did not explore the relationship between body size and abiotic factors, they found that, in both species, larger O. miniata individuals were found at sites of higher densities of the species and lower sizes where grasshopper diversity was higher (thus suggesting that interspecific competition could play a role in determining body size). Nevertheless, they suggested that sites of high density are the most ecologically favourable (central), which possibly depend on a combination of abiotic factors that maintain an environment supportive of larger body sizes.

It is thus clear that most well-studied Orthoptera follow the converse to Bergmann's rule and that the most probable explanation for these trends is not thermoregulatory but has to do with increasing seasonality, availability of resources, and growth and developmental time [10, 12, 42-45, 65, 66].

The study of abiotic factors that influence the distribution of geographic body size of animals is thus relevant from several points of view. The confluence of climatic and ecological factors affects so many life history characteristics that knowledge about the trade-offs between the biology of organisms and the environment is essential for a true comprehension of the evolutionary history of species and higher taxa as well as the impact of ongoing and prospective climatic change on their geographic distribution. In the case of Melanopline grasshoppers, and especially those of the maculipennis group treated in this paper, biotic and abiotic factors and body size variation may be correlated with complex chromosome polymorphisms. As we demonstrated in D. pratensis marginal populations occupy ecologically suboptimal environments in southern margins (Patagonia) and in high altitude in the sub-Andean populations at more than $2,400 \mathrm{~m}$ above sea level in the northwest. In these populations the morphological (and genetic) variability increases with the decrease in body size. The release of genetic variability due to high recombination would favor adaptation of natural populations to harsh environments in marginal regions. Although D. vittatus is not chromosomally polymorphic, it exhibits the same body size trends of $D$. pratensis (except for sexual size dimorphism) within the same general geographic area. Harsh abiotic and biotic conditions in marginal areas and increasing seasonality determine the shortening of the time available for growth and development, thus allowing for lower body sizes as well as small, lowdensity, sparsely distributed populations. Marginal areas are zones of continuous extinction and recolonisation according to changing climatic conditions. This is of relevance in the context of current climatic change because increasing temperature may allow the expansion of these species, which are serious crop pests in some parts of their ranges, allowing for the transformation of previous marginal areas into more favorable ones. It is thus of utmost importance to recognize abiotic and ecological body size predictors that may help understand future range expansions and prospective outbreaks.

\section{Acknowledgments}

The authors wish to thank Dr. Matilda Savopoulou-Soultani for her kind invitation to participate in this special issue of Psyche. An anonymous referee provided valuable suggestions. Valeria Ximena Rodríguez was extremely helpful in the preparation of the definitive manuscript. This work was partially financed through Grant PICTO 37035 FONCyT to D. A. Martí. E. R. Castillo is a Ph.D. candidate at Universidad Nacional de Córdoba (Ph.D. in Biological 
Sciences). C. I. Miño is thankful to CAPES (Brazil) for her postdoctoral fellowship (PRODOC 2637/2010). D. A. Martí acknowledges the continuous support of Consejo Nacional de Investigaciones Científicas y Técnicas (CONICET). C. J. Bidau acknowledges Universidad Nacional de Río Negro (Argentina) for numerous benefits in his present professorial position and dedicates this paper to his dear friend Alejandra Pilar Rendina for her endless love, continuous support, and stimulating discussions.

\section{References}

[1] M. Labarbera, "Analyzing body size as a factor in ecology and evolution," Annual Review of Ecology and Systematics, vol. 20, pp. 97-117, 1989.

[2] D. W. Whitman, "The significance of body size in the Orthoptera: a review," Journal of Orthoptera Research, vol. 17, pp. 117-134, 2008.

[3] D. J. Fielding and L. S. DeFoliart, "Relationship of metabolic rate to body size in Orthoptera," Journal of Orthoptera Research, vol. 17, pp. 301-306, 2008.

[4] J. Kozłowski, M. Konarzewski, and A. T. Gawelczyk, "Cell size as a link between noncoding DNA and metabolic rate scaling," Proceedings of the National Academy of Sciences of the United States of America, vol. 100, no. 2, pp. 14080-14085, 2003.

[5] J. Kozłowski and M. Konarzewski, "Is West, Brown and Enquist's model of allometric scaling mathematically correct and biologically relevant?" Functional Ecology, vol. 18, no. 2, pp. 283-289, 2004.

[6] A. Hônek, "Intraspecific variation in body size and fecundity in insects: a general relationship," Oikos, vol. 66, no. 3, pp. 483$492,1993$.

[7] O. Akman and D. Whitman, "Analysis of body size and fecundity in a grasshopper," Journal of Orthoptera Research, vol. 17, pp. 249-257, 2008.

[8] B. K. McNab, "Geographic and temporal correlations of mammalian size reconsidered: a resource rule," Oecologia, vol. 164, no. 1, pp. 13-23, 2010.

[9] I. Filin, O. J. Schmitz, and O. Ovadia, "Consequences of individual size variation for survival of an insect herbivore: an analytical model and experimental field testing using the Redlegged Grasshopper," Journal of Orthoptera Research, vol. 17, pp. 283-391, 2008.

[10] C. J. Bidau and D. A. Martí, "Clinal variation of body size in Dichroplus pratensis (Orthoptera: Acrididae): inversion of Bergmann's and Rensch's rules," Annals of the Entomological Society of America, vol. 100, no. 6, pp. 850-860, 2007.

[11] C. J. Bidau and D. A. Martí, "Dichroplus vittatus (Orthoptera: Acrididae) follows the converse to Bergmann's rule although male morphological variability increases with latitude," Bulletin of Entomological Research, vol. 97, no. 1, pp. 69-79, 2007.

[12] C. J. Bidau and D. A. Martí, "Geographic and climatic factors related to a body-size cline in Dichroplus pratensis Bruner, 1900 (Acrididae, Melanoplinae)," Journal of Orthoptera Research, vol. 17, pp. 149-156, 2008.

[13] J. B. Lamarck, "Philosophie Zoologique," Paris, France, 1809.

[14] C. Darwin, On the Origin of Species by Means of Natural Selection or the Preservation of Favored Races in the Struggle for Life, Murray, London, UK, 1859.

[15] A. R. Wallace, Darwinism: an Exposition of the Theory of Natural Selection with Some of Its Applications, Macmillan, London, UK, 2nd edition, 1889.
[16] C. Bergmann, "Über die Verhältnisse der Wärmeökonomie der Thiere zu ihrer Grösse," Göttinger Studien, vol. 1, pp. 595$708,1847$.

[17] J. A. Allen, "The influence of physical conditions in the genesis of species," Radical Review, vol. 1, pp. 108-140, 1877.

[18] C. L. Gloger, Das Abändern der Vögel durch Einfluss des Klimas, August Schulz, Breslau, Germany, 1833.

[19] D. S. Jordan, "Relations of temperature to vertebrae among fishes," Proceedings of the United States National Museum, vol. 1891, pp. 107-120, 1892.

[20] R. M. McDowall, “Jordan's and other ecogeographical rules, and the vertebral number in fishes," Journal of Biogeography, vol. 35 , no. 3, pp. 501-508, 2008.

[21] T. M. Blackburn, K. J. Gaston, and N. Loder, "Geographic gradients in body size: a clarification of Bergmann's rule," Diversity and Distributions, vol. 5, no. 4, pp. 165-174, 1999.

[22] V. Millien, S. Kathleen Lyons, L. Olson, F. A. Smith, A. B. Wilson, and Y. Yom-Tov, "Ecotypic variation in the context of global climate change: revisiting the rules," Ecology Letters, vol. 9, no. 7, pp. 853-869, 2006.

[23] K. J. Gaston, S. L. Chown, and K. L. Evans, "Ecogeographical rules: elements of a synthesis," Journal of Biogeography, vol. 35, no. 3, pp. 483-500, 2008.

[24] C. Watt, S. Mitchell, and V. Salewski, "Bergmann's rule; A concept cluster?” Oikos, vol. 119, no. 1, pp. 89-100, 2010.

[25] P. F. Scholander, "Climatic adaptations," Evolution, vol. 10, pp. 339-340, 1956.

[26] B. Rensch, "Some problems of geographical variation and species formation," Proceedings of the Linnean Society of London, vol. 150, pp. 275-285, 1938.

[27] B. Rensch, Evolution Above the Species Level, Columbia University Press, New York, NY, USA, 1959.

[28] E. Mayr, Animal Species and Evolution, Harvard University Press, Cambridge, Mass, USA, 1963.

[29] E. Mayr, "Geographic character gradients and climatic adaptations," Evolution, vol. 10, pp. 105-105-108, 1956.

[30] C. Ray, "The application of Bergmann's and Allen's rules to the poikilotherms," Journal of Morphology, vol. 106, pp. 85-108, 1960.

[31] H. D. Prange, "Temperature regulation by respiratory evaporation in grasshoppers," Journal of Experimental Biology, vol. 154, pp. 463-474, 1990.

[32] P. E. Hertz, R. B. Huey, and R. D. Stevenson, "Evaluating temperature regulation by field-active ectotherms: the fallacy of the inappropriate question," American Naturalist, vol. 142, no. 5, pp. 796-818, 1993.

[33] S. J. Willott, "Thermoregulation in four species of British grasshoppers (Orthoptera: Acrididae)," Functional Ecology, vol. 11, no. 6, pp. 705-713, 1997.

[34] S. Springate and M. B. Thomas, "Thermal biology of the meadow grasshopper, Chorthippus parallelus, and the implications for resistance to disease," Ecological Entomology, vol. 30, no. 6, pp. 724-732, 2005.

[35] K. M. O’Neill and M. G. Rolston, "Short-term dynamics of behavioral thermoregulation by adults of the grasshopper Melanoplus sanguinipes," Journal of Insect Science, vol. 7, article 27, 2007.

[36] M. S. Boyce, "Seasonality and patterns of natural selection for life histories," The American Naturalist, vol. 114, pp. 569-583, 1979.

[37] S. L. Lindstedt and M. S. Boyce, "Seasonality, fasting endurance, and body size in mammals," The American Naturalist, vol. 125, no. 6, pp. 873-878, 1985. 
[38] A. I. Medina, D. A. Martí, and C. J. Bidau, "Subterranean rodents of the genus Ctenomys (Caviomorpha, Ctenomyidae) follow the converse to Bergmann's rule," Journal of Biogeography, vol. 34, no. 8, pp. 1439-1454, 2007.

[39] W. U. Blanckenhorn and M. Demont, "Bergmann and converse bergmann latitudinal clines in arthropods: two ends of a continuum?" Integrative and Comparative Biology, vol. 44, no. 6, pp. 413-424, 2004.

[40] M. M. Cigliano and D. Otte, "Revision of the Dichroplus Maculipennis species group (Orthoptera, Acridoidea, Melanoplinae)," Transactions of the American Entomological Society, vol. 129, no. 1, pp. 133-162, 2003.

[41] N. E. Sánchez and M. L. de Wysiecki, "Abundancia y diversidad de acridios en pasturas de la Provincia de La Pampa," Revista de Investigaciones Agropecuarias Argentinas, vol. 24, pp. 29-39, 1993.

[42] S. Masaki, "Geographic variation and climatic adaptation in a field cricket (Orthoptera: Gryllidae)," Evolution, vol. 21, pp. 725-741, 1967.

[43] S. Masaki, "Seasonal and latitudinal adaptations in the life cycles of crickets," in Evolution of Insect Migration and Diapause, H. Dingle, Ed., pp. 72-100, Springer, New York, NY, USA, 1978.

[44] T. A. Mousseau and D. A. Roff, "Adaptation to seasonality in a cricket: patterns of phenotypic and genotypic variation in body size and diapause expression along a cline in season length," Evolution, vol. 43, no. 7, pp. 1483-1496, 1989.

[45] T. A. Mousseau, "Ectotherms follow the converse to Bergmann's rule," Evolution, vol. 51, pp. 630-632, 1997.

[46] C. J. Bidau and D. A. Martí, "A test of Allen's rule in ectotherms: the case of two south American Melanopline Grasshoppers (Orthoptera: Acrididae) with partially overlapping geographic ranges," Neotropical Entomology, vol. 37, no. 4, pp. 370-380, 2008.

[47] J. A. Allen, "The evolution of species through climatic conditions," Science, vol. 22, no. 569, pp. 661-668, 1905.

[48] J. Peat, B. Darvill, J. Ellis, and D. Goulson, "Effects of climate on intra- and interspecific size variation in bumble-bees," Functional Ecology, vol. 19, no. 1, pp. 145-151, 2005.

[49] M. A. Serrat, D. King, and C. O. Lovejoy, "Temperature regulates limb length in homeotherms by directly modulating cartilage growth," Proceedings of the National Academy of Sciences of the United States of America, vol. 105, no. 49, pp. 19348-19353, 2008.

[50] C. J. Bidau and D. A. Martí, "Geographic distribution of Robertsonian fusions in Dichroplus pratensis (Melanoplinae, Acrididae): the central-marginal hypothesis reanalysed," Cytogenetic and Genome Research, vol. 96, no. 1-4, pp. 66-74, 2002.

[51] D. S. Tosto and C. J. Bidau, "Distribution of chromosome frequencies within a hybrid zone of Dichroplus pratensis (Melanoplinae, Acrididae)," Heredity, vol. 67, pp. 299-206, 1991.

[52] B. Rensch, "Die Abhängigkeit der relativen Sexualdifferenz von der Körpegröße," Bonner Zoologische Beiträge, vol. 1, pp. 58-69, 1950.

[53] D. J. Fairbairn, "Allometry for sexual size dimorphism: pattern and process in the coevolution of body size in males and females," Annual Review of Ecology and Systematics, vol. 28, pp. 659-687, 1997.

[54] C. J. Bidau and D. A. Martí, "Rensch's rule in Dichroplus pratensis: a reply to Wolak," Annals of the Entomological Society of America, vol. 101, no. 5, pp. 802-803, 2008.
[55] T. J. Webb and R. P. Freckleton, "Only half right: species with female-biased Sexual Size Dimorphism consistently break Rensch's rule," PLoS One, vol. 2, no. 9, article e897, 2007.

[56] A. Hochkirch and J. Gröning, "Sexual size dimorphism in Orthoptera (sens. str.)-a review," Journal of Orthoptera Research, vol. 17, pp. 189-196, 2008.

[57] W. U. Blanckenhorn, R. C. Stillwell, K. A. Young, C. W. Fox, and K. G. Ashton, "When Rensch meets Bergmann: does sexual size dimorphism change systematically with latitude?" Evolution, vol. 60, no. 10, pp. 2004-2011, 2006.

[58] C. J. Bidau and D. A. Martí, "Contrasting patterns of sexual size dimorphism iin the grasshoppers Dichroplus vittatus and D. pratensis (Melanoplinae, Acrididae)," Journal of Orthoptera Research, vol. 17, pp. 201-208, 2008.

[59] C. I. Miño, C. N. Gardenal, and C. J. Bidau, "Morphological, genetic, and chromosomal variation at a small spatial scale within a mosaic hybrid zone of the grasshopper Dichroplus pratensis Bruner (Acrididae)," Journal of Heredity, vol. 102, no. 2, pp. 184-195, 2011.

[60] C. J. Bidau, "Multivalents resulting from monobrachial homologies within a hybrid zone in Dichroplus pratensis (Acrididae): meiotic orientation and segregation," Heredity, vol. 66, pp. 219-232, 1991.

[61] M. B. Chiappero, C. Parise, D. A. Martí, C. J. Bidau, and C. N. Gardenal, "Distribution of genetic variability in populations of two chromosomal races of Dichroplus pratensis (Melanoplinae, Acrididae) and their hybrid zone," Journal of Evolutionary Biology, vol. 17, no. 1, pp. 76-82, 2004.

[62] G. U. C. Lehmann and A. W. Lehmann, "Variation in body size among populations of the bushcricket Poecilimon thessalicus (Orthoptera: Phaneropteridae): an ecological adaptation?" Journal of Orthoptera Research, vol. 17, pp. 165-169, 2008.

[63] V. Fabriciusová, P. Kaňuch, and A Krištín, "Body size patterns of Pholidoptera frivaldskyi (Orthoptera) in very isolated populations," Journal of Orthoptera Research, vol. 17, pp. 171-176, 2008.

[64] B. Ciplak, D. Sirin, M. Sait Teylan, and S. Kaya, "Altitudinal size clines, species richness and population density: case studies in Orthoptera," Journal of Orthoptera Research, vol. 17, pp. 157-163, 2008.

[65] D. Roff, "Optimizing development time in a seasonal environment: the 'ups and downs' of clinal variation," Oecologia, vol. 45, no. 2, pp. 202-208, 1980.

[66] M. G. Telfer and M. Hassall, "Ecotypic differentiation in the grasshopper Chorthippus brunneus: life history varies in relation to climate," Oecologia, vol. 121, no. 2, pp. 245-254, 1999. 

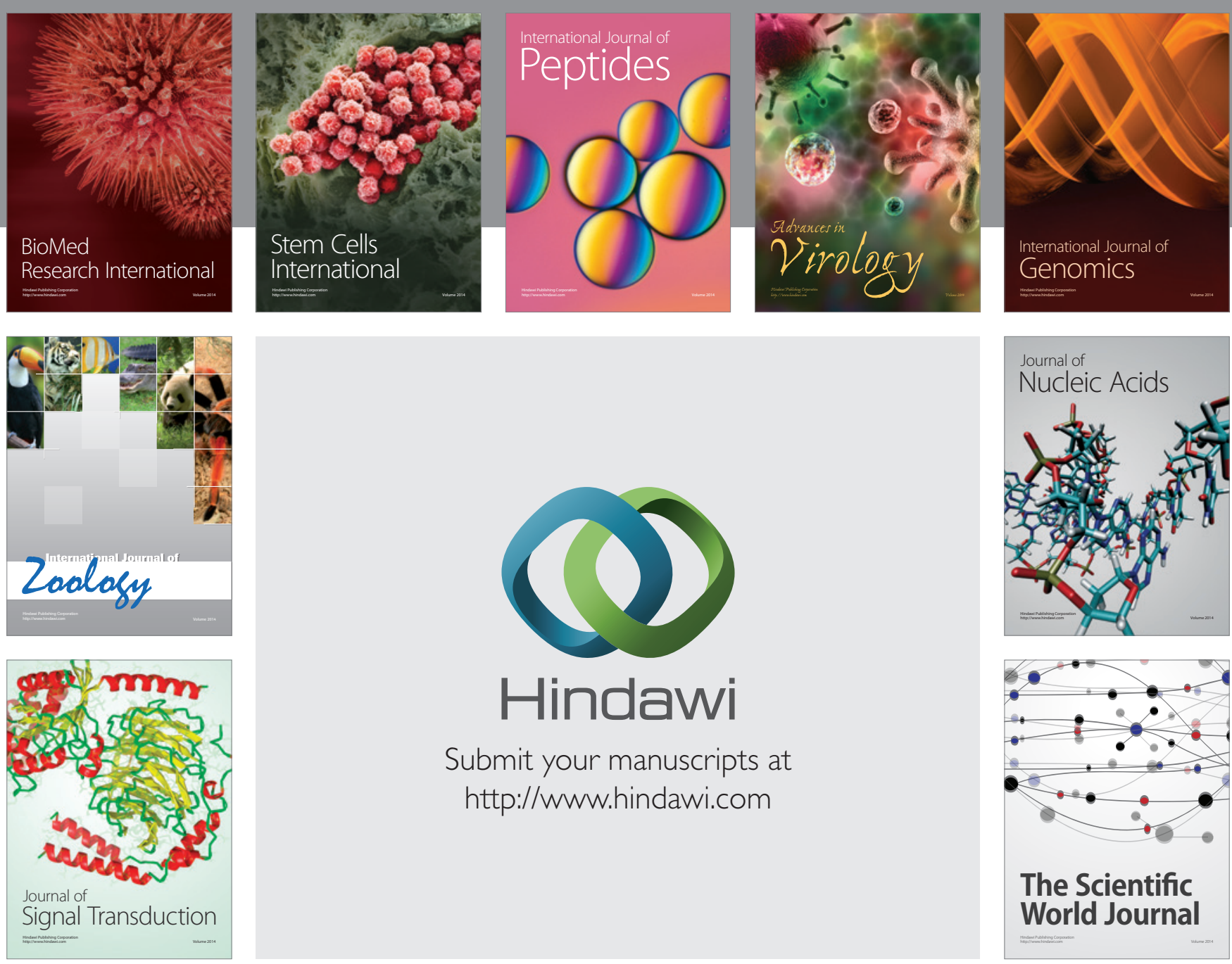

Submit your manuscripts at

http://www.hindawi.com
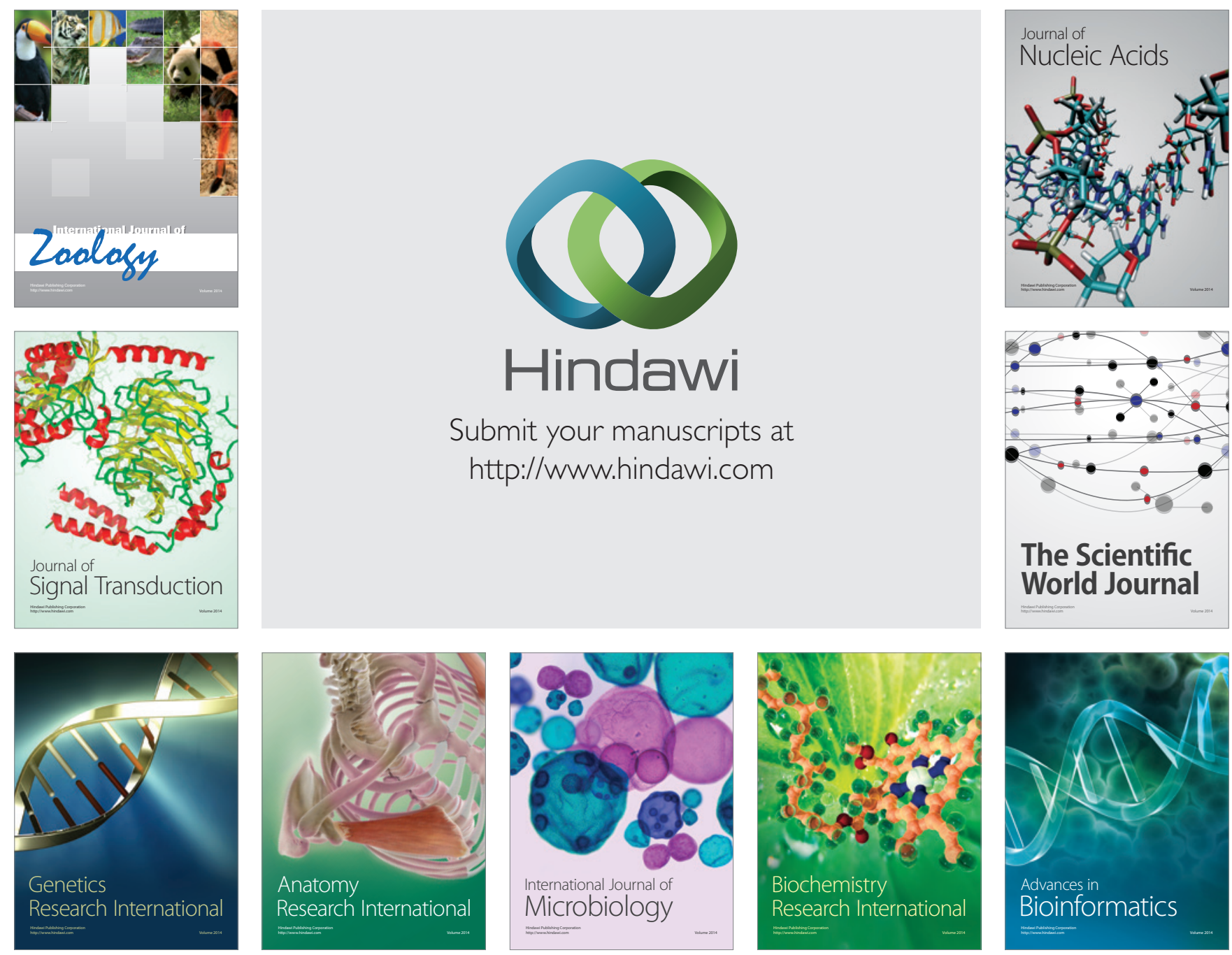

The Scientific World Journal
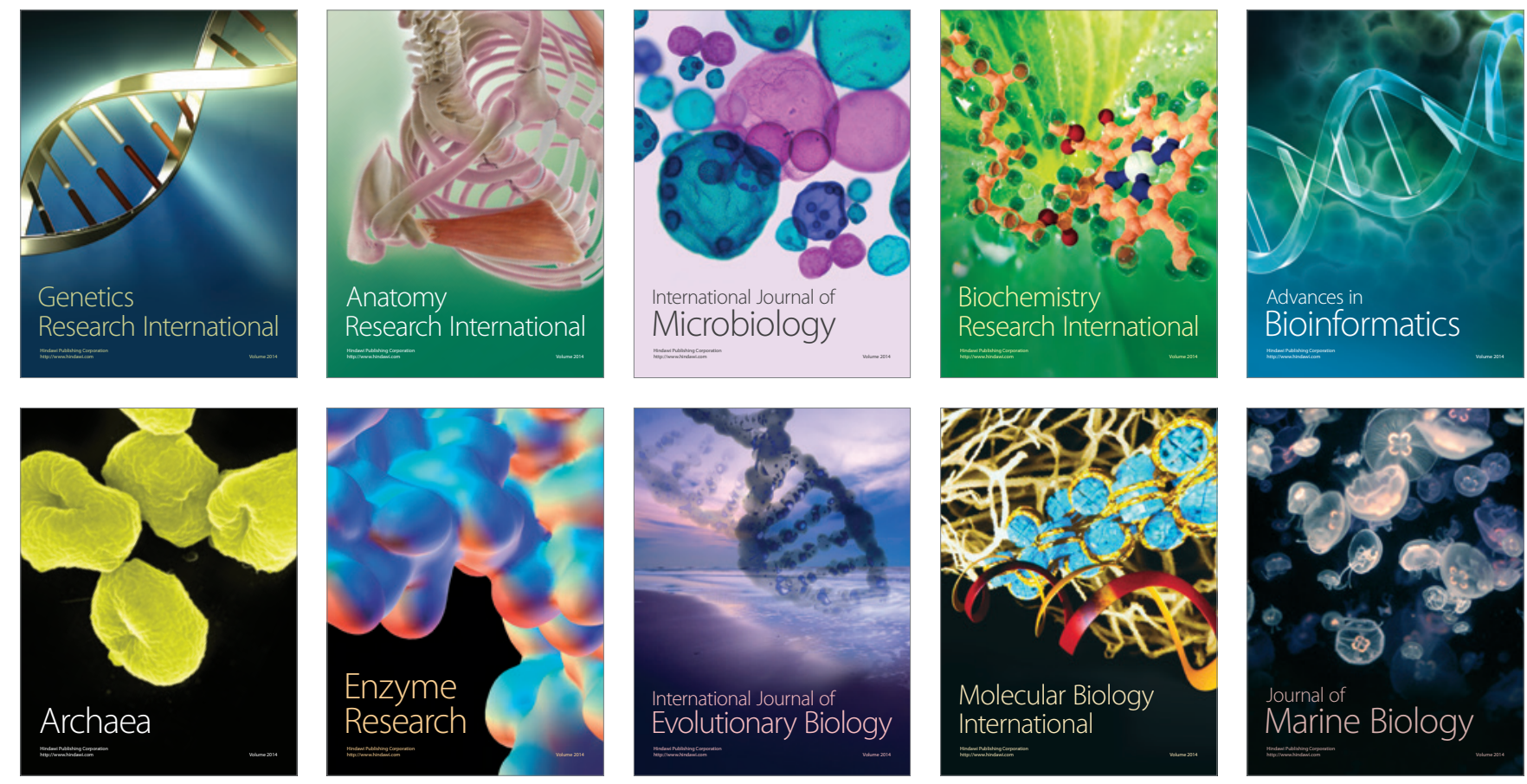